\title{
A UTILIZAÇÃO DE METODOLOGIAS PARTICIPATIVAS DE INVESTIGAÇÃ̃O E ATUAÇÃO EM TERRITÓRIOS POPULARES: O PROBLEMA DE ACESSO À ÁGUA EM TEMPOS DE PANDEMIA
}

\section{THE USE OF PARTICIPATORY RESEARCH METHODOLOGIES AND PERFORMANCE IN POPULAR TERRITORIES: THE PROBLEM OF ACCESS TO WATER IN TIMES OF \\ PANDEMIC}

\author{
Fernando Botton ${ }^{(1)}$ \\ Mestrando em Planejamento e Gestão do Território pela Universidade Federal do ABC (UFABC-PGT \\ Sheila Cristiane Santos Nobre ${ }^{(2)}$ \\ Pesquisadora e Liderança Comunitária pela União dos Movimentos de Moradia - UMM/SP. \\ Marilene Ribeiro de Souza ${ }^{(3)}$ \\ Pesquisadora e Liderança Comunitária pela União dos Movimentos de Moradia - UMM/SP. \\ Benedito Roberto Barbosa ${ }^{(4)}$ \\ Doutorando em Planejamento de Gestão do Território pela Universidade Federal do ABC (UFABC-PGT). \\ Vanessa Lucena Empinotti ${ }^{(5)}$ \\ Professora Doutora da Universidade Federal do ABC e pesquisadora do LabJuta/UFABC.
}

E-mail ${ }^{(1)}$ : f.botton@ufabc.edu.br

\section{RESUMO}

A concepção da pesquisa-extensão “Cartografias de acesso à água na pandemia do Covid-19” foi desenvolvida de maneira articulada entre parceiros de um Laboratório de Pesquisa e Extensão Universitária, entre eles a UMM - União dos Movimentos de Moradia. O projeto teve como objetivo identificar, compreender e mapear as dificuldades no acesso à água em locais com moradias precária no município de São Paulo, durante a pandemia da Covid-19. Para isso, utilizou de metodologias de investigação e atuação no território e contou com a participação de pesquisadores populares. Numa primeira etapa, foram coletadas informações por meio de um questionário eletrônico, voltado somente para os moradores de áreas precárias. Em um desdobramento da pesquisa, a partir de uma visão geral do problema, foram feitas entrevistas em profundidade em nove comunidades selecionadas em conjunto com os movimentos de moradia, a fim de detalhar as histórias de falta d'água e construir diferentes cartografias.

\begin{abstract}
The conception of the extension research "Maps of access to water in the Covid-19 pandemic" was developed in an articulated way between partners of a Research and University Extension Laboratory, among them the UMM - Union of Housing Movements. The project aimed to identify, understand and map the difficulties in accessing water in places with precarious housing in the city of São Paulo, during the Covid-19 pandemic. For this, it used research and action methodologies in the territory and had the participation of popular researchers. In a first step, information was collected through an electronic questionnaire, aimed only at residents of precarious areas. As a result of the research, from an overview of the problem, in-depth interviews were conducted in nine communities selected together with the housing movements, in order to detail the stories of water shortages and build different cartographies.
\end{abstract}

Palavras-chave: metodologia. pesquisa-ação. assentamentos precários. insegurança hídrica.

Key words: methodology. action research. precarious settlements. water insecurity.

\section{INTRODUÇÃO}

O acesso à moradia adequada pela população de baixa renda, associado as questões de saneamento, é um problema estrutural na urbanização desigual brasileira e se expressa no território (REZENDE; 
HELLER, 2008; FERRARA et al, 2019). A desigualdade de renda, a concentração de propriedades privadas por poucos indivíduos, a valorização imobiliária em regiões infraestruturadas (que eleva os preços dos imóveis e aluguéis em geral), somada à uma insuficiente e inadequada política pública habitacional são, resumidamente, alguns fatores centrais explicativos da permanente crise habitacional (KOWARICK, 1979; MARICATO, 1996). Durante a pandemia da Covid-19, se evidenciaram muitas das preocupações existentes com os moradores de áreas precárias, favelas e ocupações, devido a condição de precariedade em que vivem. Entretanto, a questão do acesso à água se tornou chave uma vez que é uma condicionante para que as pessoas possam se proteger contra o vírus da Covid-19.

Os processos de urbanização são também responsáveis pela produção de condições que levam a insegurança hídrica, onde os indivíduos não têm condições de garantir o acesso à água em quantidade e qualidade (Jepson et all, 2007). Ao identificar os níveis de insegurança hídrica, são analisadas não somente a presença ou não de infraestrutura, mas também a qualidade e quantidade de distribuição da água e seu impacto no dia a dia das pessoas. Ou seja, domicílios ligados a rede de abastecimento não indicam a existência de condições de segurança hídrica por si só, é necessário avaliar o impacto da disponibilização da água no dia a dia das pessoas. Além disso, o engajamento social e a mobilização são essenciais para o alcance de uma segurança hídrica. Estas práticas hidrossociais são capazes de aumentar a equidade social e empoderar as comunidades urbanas (Empinotti et al., 2021). Nesse sentido, tornou-se evidente a inquietação e a necessidade de aprofundar o conhecimento sobre o tema nestes territórios populares, entendendo que não há informações públicas e detalhadas sobre o acesso à água nas favelas. Assim, o objetivo deste artigo é apresentar a metodologia desenvolvida para coletar os dados que nos possibilitaram entender e documentar os problemas de acesso à água em favelas, ocupações e comunidades durante a pandemia, tendo como protagonistas as pesquisadoras populares, membras da União dos Movimentos de Moradia de São Paulo (UMM) e conhecedoras dos territórios, parceiras chave na elaboração e condução desta pesquisa.

\section{ETAPAS DE PESQUISA E METODOLOGIA}

O ponto de partida para o desenvolvimento deste documento foi o projeto de pesquisa e extensão “Cartografias de acesso à água na pandemia do Covid-19", desenvolvido entre março de 2020 e março de 2021, com a participação de pesquisadores de um Laboratório de Pesquisa e Extensão Universitária em parceria com outros Laboratórios Universitários e Instituições, além da presença essencial de lideranças da União dos Movimentos de Moradia (UMM) e da Central de Movimentos Populares (CMP). O método orientativo geral para o desenvolvimento da metodologia do trabalho se baseou nos fundamentos da pesquisa-ação que formula a participação direta dos envolvidos na pesquisa em uma co-construção horizontal e participativa de conhecimento (Thiollent, 1994). A proposta do projeto surgiu a partir de relatos das lideranças locais e moradores que participavam de reuniões remotas para que os pesquisadores pudessem acompanhar o que estava acontecendo nos territórios populares. Um dos problemas identificados foi a dificuldade de conversar com a companhia de abastecimento local - Sabesp, sobre a necessidade de disponibilizar e garantir o abastecimento de água nestas áreas. Tal questionamento indicou a necessidade de entendermos como o acesso à água estava ocorrendo na pandemia e como os problemas se configuravam. Buscando manter o caráter da pesquisa participante e também extensionista, foi inicialmente concebido por este grupo multidisciplinar de pesquisadores acadêmicos e populares um questionário sobre o acesso à água nas favelas e ocupações, como meio possível de identificar locais e caracterizar algumas situações onde o problema estava ocorrendo. A partir desta iniciativa, um desenho metodológico foi proposto para que fosse possível coletar os dados necessários para a realização da pesquisa. Tal desenho foi elaborado para a coleta de dados em dois momentos. O primeiro foi a aplicação de um questionário on-line. O segundo momento de coleta de dados ocorreu por meio de entrevistas individuais com 
lideranças e moradores de nove localidades. A seguir explicaremos as etapas que construíram a coleta de dados para esta pesquisa.

\subsection{Primeira etapa da pesquisa - aplicação de um questionário online}

No contexto da pandemia da Covid-19, o questionário online passou a ser uma ferramenta potente e viável de pesquisa não presencial e que assumiu, na pesquisa desenvolvida, um caráter pioneiro por ser aplicada como uma das ferramentas de coleta de dados em um desenho de pesquisa-ação desenvolvido no contexto de assentamentos precários e de baixa renda. Apesar das desvantagens como o baixo número de respostas e a baixa confiabilidade nos dados uma vez que estes não são passíveis de verificação (Vasconcelos e Guedes, 2007), este método foi escolhido por possibilitar a coleta de dados de forma remota e segura em um contexto de pandemia onde é necessária a redução do contato entre as pessoas, assim como a sua mobilidade.

O questionário eletrônico concebido nesta pesquisa não corresponde a um survey quantitativo, ou seja, a coleta de informações não se baseou em amostra pré-definida, o que não permite que os resultados sejam utilizados para aferir generalizações. Assim, trata-se de pesquisa qualitativa, de caráter interpretativo, que utiliza o formulário eletrônico como ferramenta de coleta de informações e permite identificar problemas sobre a dificuldade no acesso à água vivido por indivíduos em situação de precariedade habitacional. Uma das perguntas do questionário foi o CEP (Código de Endereçamento Postal) do domicílio do participante, ou o CEP de algum local próximo de referência. A coleta desta informação foi importante para localizar a área (assentamento ou bairro) e também para que parte das respostas pudessem ser georreferenciada e especializada em mapas. Desde o início, houve a preocupação com o anonimato dos respondentes. Por isso, não foram demandas informações de identificação pessoal. As outras questões se referiam a existência ou não de caixa d'água no domicílio, na identificação de estratégias para garantir a disponibilidade da água nas residências, a frequência da falta de água, o custo e impacto da tarifa ou da compra de água engarrafada na renda familiar.

$\mathrm{Na}$ etapa de formulação do questionário, as questões foram elaboradas com o objetivo de serem facilmente compreendidas pelo público-alvo. Além da linguagem coloquial, o formulário tinha um número reduzido de questões, para que pudesse ser respondido num curto espaço de tempo, principalmente via celular. Optou-se pela utilização do Google Forms por se tratar de ferramenta gratuita, com interface de fácil compreensão e sem limite de número máximo de respostas.

A divulgação do formulário eletrônico contou com a estratégia de difusão da informação por meio de redes sociais como: divulgação no Facebook, na página do Laboratório Justiça Territorial e também nas páginas dos membros do projeto; divulgação via Whatsapp, em grupos e com mensagens direcionadas a indivíduos considerados estratégicos para a propagação do questionário; realização de cartaz digital para impulsionamento nas semanas finais de coleta, para divulgação nas rede mencionadas acima. Outro trabalho fundamental e que impulsionou o número de respostas do questionário foi a ligação para lideranças comunitárias (de cortiços, ocupações, favelas e sedes de associações de moradores) a partir de uma lista de contato telefônico fornecida pelos parceiros dos movimentos de moradia com mais de 150 lideranças. A diretriz era que respondessem o questionário e repassassem em suas outras redes, numa estratégia similar ao da "bola de neve". Na fase final de aplicação do questionário, um novo contato com algumas destas lideranças foi retomado a fim de atingir um maior número de respostas.

Até a data de 04/06/2020 quando o questionário foi tirado do ar, foram coletadas 591 respostas na Região Metropolitana de São Paulo (RMPS). O município de São Paulo contou com 549 respostas e o restante das respostas ficou dividida entre os municípios de Carapicuíba, Diadema, Embu das Artes, Guarulhos, Itapecerica da Serra, Mauá, Mogi das Cruzes, Osasco, Ribeirão Pires, São Bernardo e 
Santo André, municipios que possuem uma boa capilaridade de atuação da UMM. Optou-se por trabalhar somente no município de São Paulo, pelo maior número de respostas e pela facilidade de articulação com as lideranças destes territórios.

\subsection{Segunda etapa da pesquisa - entrevistas estruturadas}

A partir da sistematização do questionário e sua análise, foi possível identificar locais e situações em que os problemas de acesso à água eram mais significativos, o que levou a um segundo momento de aprofundamento da pesquisa. Nesta etapa, foram realizadas entrevistas individuais em profundidade com uma liderança local e três moradores, todos indicados pela UMM. As questões da entrevista estruturada foram elaboradas por professores e estudantes e depois discutidas e ajustadas com os pesquisadores da UMM.

Foram selecionados nove assentamentos no município de São Paulo para o desenvolvimento de

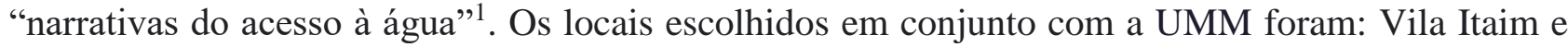
Wilma Flor na região Leste 2, Terra Prometida na região Leste 1, Ocupação PenaForte Mendes na região Central, Fazendinha na região Noroeste, São Savério/Jd. Celeste na região Sudeste, Ocupação Anchieta, Chácara do Conde e Jardim Emburá na região Sul 2. Optou-se por escolher ao menos uma comunidade de cada região do munícipio, utilizando os limites regionais a partir do referencial adotado pelos movimentos sociais, diferente dos limites utilizados pela prefeitura, escolha essa em vista da própria rede de envolvidos na conceitualização do projeto. As entrevistas em campo foram conduzidas por duas pesquisadoras populares da UMM que trabalham com as lideranças locais de cada uma das comunidades estudadas. A partir da primeira versão das questões elaboradas para a entrevista, foi conduzido um teste, onde as pesquisadoras populares foram entrevistadas para avaliar a ferramenta. Suas observações serviram para rever as questões e reestruturar o questionário norteador das entrevistas. Antes de irem à campo, as pesquisadoras foram orientadas em como aplicar as entrevistas, gravar os relatos, sistematizar as informações coletadas e armazenar o material de maneira organizada em um servidor seguro. Elas também foram instruídas em como capturar dados por meio de fotos e vídeos dos locais, assim como anotações e observações dos contextos em que ocorreram as entrevistas. Estes documentos também compuseram parte dos dados qualitativos coletados e analisados. A voz dos entrevistados foi gravada e posteriormente transcrita e sistematizada pelo restante da equipe. As visitas em campo seguiram um protocolo de segurança com utilização de máscaras e orientação para evitar locais fechados e com aglomeração no momento da aplicação das entrevistas.

\subsection{A análise dos dados:}

\section{Relatos de pesquisadoras populares por meio de seus cadernos de campo}

Os dados coletados a partir do questionário online e das entrevistas estruturadas nos possibilitaram a combinação entre uma análise especializada do acesso à água em áreas vulneráveis do município de São Paulo com o aprofundamento do entendimento de tais problemas ${ }^{1}$. Entretanto, o que queremos apresentar neste artigo é a leitura e contribuição das anotações das pesquisadoras populares sobre as realidades observadas que proporcionou uma troca de experiência neste processo de pesquisa-ação.

A experiência empírica das pesquisadoras populares em como interagir com os moradores criou a oportunidade de capturar as dificuldades dos moradores em não ter acesso à água assim como as múltiplas dimensões impactadas.

\footnotetext{
${ }^{1}$ As narrativas e todos os dados coletados na pesquisa foram sistematizadas em histórias de falta d'água, que podem ser consultadas no site https://aguaemoradia.pesquisa.ufabc.edu.br/narrativas/, acesso em acesso em 10 out. 21.
} 
A seguir seguem as principais observações realizadas à campo e relatadas pelas pesquisadoras:

No Jardim São Savério, duas realidades ocorrem dentro do território. Por um lado, uma comunidade que foi construída por processo de mutirão por autogestão, organizada e planejada com infraestrutura de água, esgoto e saneamento básico. Por outro lado, uma comunidade que enfrenta dificuldades no abastecimento da água e falta de água no período noturno. Segundo elas "várias mulheres chefes de família tinham muita dificuldade ao chegar do trabalho e sem uma caixa de água, tinham que sair a procura de água na vizinhança para abastecer a casa. E aí iam tomar banho e fazer as tarefas".

A Ocupação Anchieta é uma comunidade localizada na região do Grajaú, extremo sul do município, conformada por aproximadamente 1000 barracos e território onde as lideranças vem buscando políticas públicas para atender a população local. Pelo Programa Água Legal da Prefeitura, metade da comunidade já possui água encanada e a outra aguarda ainda ser atendida e continua lutando por esse direito.

$\mathrm{Na}$ Comunidade Fazendinha, as pesquisadoras notaram o quanto os moradores sofrem pela falta de água. Segundo suas anotações, "os moradores utilizam a mangueira para ter acesso à água, porém, muitas vezes elas ressecam e causam rachaduras ou furam e isso gera a perda da água e acaba gerando um custo extra para os moradores".

Na Ocupação Terra Prometida, a comunidade vem lutando pelo direito à moradia e pelo direito à água, dentro de um guarda-chuva de reivindicações, parte do processo de regularização fundiária pelo direito à terra e à cidade

Na Vila Itaim - Pantanal, extremo leste do município, as pesquisadoras "notaram o quanto os moradores estão em local vulnerável, vivendo de maneira insalubre e muito próximas ao rio. Uma situação muito impactante". Neste local, a população transporta água com mangueira desde um ponto de água até suas casas.

A Comunidade Vilma Flor foi construída por regime de mutirão por autogestão e possui rede de abastecimento formal fornecido pela SABESP. Apesar disso os moradores sofrem com a intermitência pela falta de pressão na rede e os mesmos relatam não acharem justo, já que pagam tão caro pelo serviço e entendem ser um direito humano básico.

A Comunidade Chácara do Conde, localizada na zona sul 2 do município, também foi construída por meio de mutirão em meados da década de 80 e apesar de possuírem rede de abastecimento formal fornecido pela SABESP, também sofrem com intermitência pela diminuição da pressão e os entrevistados relatam que isso acaba impactando nas tarefas domésticas do dia a dia.

Comunidade Jardim São Pedro - Emburá deixou as pesquisadoras perplexas ao ver que depois de 30 anos de luta pelo acesso à água, até hoje esse direito não foi conquistado. Na comunidade que possui 400 famílias, foi relatado por meio das entrevistas, as dificuldades dos moradores em lavar suas roupas e utilizar a água para beber ou cozinhar, já que uma mina suja e contaminada é a única fonte de água do local. Os abastecimentos de água fornecidos por caminhão pipa pelo poder público gratuitamente diminuíram consideravelmente neste período de pandemia.

Esta experiência, segundo os relatos das pesquisadoras, contribuiu muito para a sua formação como pesquisadoras e lideranças, pois começaram a se atentar para as questões e as e problemáticas relacionadas à água e como isso reflete no dia a dia das pessoas. Além disso, que não se pode cruzar os braços e aceitar algumas situações que parecem estarem impostas pela sociedade. Segundo elas, entrevistar pessoas que admiram como lideranças e ouvir os seus relatos, sobre os seus ganhos e perdas nessa trajetória de luta, trouxe às pesquisadoras um combustível a mais para continuar suas trajetórias como lideranças dentro do movimento e também como estudantes e pesquisadoras. 


\section{RESULTADOS ALCANÇADOS}

A partir dos dados levantados foi possível observar que os problemas de acesso à água são diversos. Por meio das informações levantadas foi possível identificar algumas categorias de problemas de acesso à água nas favelas e ocupações como: ausência de redes e realização de ligações alternativas, áreas providas de redes e mesmo assim com problemas de intermitência devido à redução de pressão no período noturno, assentamentos com ligações alternativas, a compra ou o empréstimo de água impactando no dia a dia do morador e por último a dificuldade de pagar as tarifas, mesmo que seja tarifa social. Percebeu-se também que tais condições se agravam quando os problemas aparecem de maneira combinada.

Observou-se com essa pesquisa que processos baseados em métodos qualitativos, apesar de não serem possíveis de generalização, demonstraram que na maioria dos assentamentos precários estudados existe algum tipo de problema de acesso à água, independente da sua categoria. A segunda etapa da pesquisa demonstrou a fragilidade destas comunidades e como a insegurança hídrica impacta o diaa-dia destas pessoas. Por fim, os dados levantados pelas pesquisadoras populares a partir de suas observações demonstrou o quanto faltam políticas públicas mais efetivas relacionadas ao saneamento básico para estes territórios populares e que o problema vai além da presença ou não de infraestrutura formal estabelecida, mas também está relacionada a capacidade de pagar pelo serviço de abastecimento e aos problemas de intermitência no fornecimento de água.

\section{CONCLUSÕES}

Como reflexão final é importante chamar atenção para a metodologia desenvolvida e as diferentes estratégias para coletar as informações necessárias e conseguir chegar no território num contexto de isolamento social como o da pandemia. Esta pesquisa não teria acontecido sem uma forte articulação com os nossos parceiros populares, que ocorreu em vários momentos, desde a elaboração do material, passando pela divulgação com as redes para a coleta de dados do questionário online até o momento de ida à campo para a aplicação das entrevistas. A relação estabelecida entre o Laboratório de Justiça Territorial e as lideranças da UMM por meio de trabalhos de pesquisa anteriores, contribuiu para o fortalecimento e uma melhor coleta de dados. Os resultados positivos também foram resultado do comprometimento das pesquisadoras populares em campo e a experiência compartilhada na elaboração das ferramentas de coleta, desenvolvimento da estratégia de coleta dos dados e da capacidade de análise desenvolvida. Por fim, como cita uma das pesquisadoras populares do projeto "A minha maior tristeza foi ver nestes locais a situação a falta de políticas públicas, como se fossem excluídos. Só são lembrados quando e para somar no censo, ser mais um no mapa da miséria."

\section{REFERÊNCIAS}

EMPINOTTI, V. L. Et al. Advancing urban water security: The urbanization of water-society relations and entry-points for political engagement, Water International, 2021.

FERRARA, L. N. et al. Saneamento básico e urbanização de favelas: os desafios de universalização à luz das especificidades de ocupação dos assentamentos precários, in:

FERREIRA, L.; OLIVEIRA, P.; IACOVINI, V.; (org.) Dimensões do intervir em favelas: desafios e perspectivas. São Paulo: Peabiru TCA e Coletivo Lablaje, v. 1, p. 104-111, 2019.

JEPSON, W.; BUDDS, J.; EIC ELBERGER, L.; ARRIS, L.; NORMAN, E.; O'REILLY, K.; PEARSON, A.; SHAH, S.; SHINN, J; STADDON, C.; STOLER, J.; WUTICH, A.; YOUNG, S. L. Advancing Human Capabilities for Water Security: A Relational Approach. Water Security, v. 1, p. 46-52, 2017. 
KOWARICK, L. A espoliação urbana. Rio de Janeiro: Paz e Terra, 1979.

MARICATO, E. Metrópole na periferia do capitalismo. São Paulo: Hucitec, 1996.

REZENDE, S. C.; HELLER, L. O saneamento no Brasil: políticas e interfaces. Belo Horizonte: Editora UFMG, 2008.

THIOLLENT, M. Metodologia da pesquisa-ação. São Paulo. Cortez, 1994.

VASCONCELLOS-GUEDES, L.; GUEDES, L. F. A. E-surveys: Vantagens e Limitações dos Questionários Eletrônicos via Internet no Contexto da Pesquisa Científica. In: X SemeAd Seminário em Administração FEA/USP (São Paulo, Brasil), 2007. 